\title{
Pulmonary deposition and disappearance of aerosolised secretory leucocyte protease inhibitor
}

\author{
J Stolk, J Camps, H I J Feitsma, J Hermans, J H Dijkman, E K J Pauwels
}

\begin{abstract}
Background - The neutrophil elastase inhibitor, secretory leucocyte protease inhibitor (SLPI), is a potential therapeutic tool in inflammatory lung diseases such as cystic fibrosis and pulmonary emphysema. The distribution and disappearance in the lung of aerosolised recombinant SLPI (rSLPI) was investigated in healthy humans and in patients with cystic fibrosis or $\alpha_{1}$-antitrypsin-associated emphysema.

Methods - To distinguish aerosolised rSLPI from endogenous SLPI the recombinant inhibitor was radiolabelled with 99m-technetium $\left({ }^{99 m} \mathrm{Tc}\right)$ pertechnetate. Distribution and disappearance of aerosolised ${ }^{99 \mathrm{~m}}$ Tc-rSLPI in the lungs were studied by gamma radiation imaging.

Results - The deposition of ${ }^{99 m}$ Tc-rSLPI in normal volunteers was homogeneous in all lung lobes, while in patients with cystic fibrosis or emphysema only well ventilated areas showed deposition of the aerosol. The disappearance rate of ${ }^{99 \mathrm{~m}}$ Tc-rSLPI was biexponential. The half life of the rapid phase was $0 \cdot 2-2 \cdot 8$ hours, while that of the slow phase was more than 24 hours. Conclusions - Future aerosol therapy with rSLPI will be most beneficial for well ventilated lung tissue that needs protection against neutrophil derived elastase. It may be more difficult to neutralise the burden of elastase in poorly ventilated, highly inflamed areas as are seen in cystic fibrosis. (Thorax 1995;50:645-650)
\end{abstract}

Department

J Stolk

J H Dijkman

Department of

Diagnostic Radiology and Nuclear Medicine

J Camps

H I J Feitsma

E K J Pauwels

Department of Medical Statistics

J Hermans

University Hospital, Leiden, 2300 RC, Leiden,

The Netherlands

Reprint requests to: Prof Dr J H Dijkman.

Received 18 February 1994 Returned to authors 6 May 1994

Revised version received

26 January 1995

26 January 1995

16 February 1995
This suggests that SLPI also diffuses into interstitium. In vitro studies with cultured bronchial gland cells have shown that secretory proteins such as SLPI and lysozyme are secreted at both apical and basal sites of the cells, suggesting that these cells have vectorial delivery. $^{6}$

Proteinases including neutrophil elastase and cathepsin $\mathrm{G}$ are released from neutrophils during bacterial infection in the human airways in cystic fibrosis or in chronic obstructive pulmonary disease (COPD) ${ }^{78}$ Treatment with SLPI may improve bacterial phagocytosis by neutrophils due to protection of cell surface receptors and opsonins against elastase-mediated degradation..$^{910}$ Moreover, it may reduce the production of mucins, since free elastase is one of the most potent stimuli of mucin production in the airways. ${ }^{11}$

SLPI is now available by recombinant DNA technology. ${ }^{12}$ It is not efficient to administer rSLPI orally or intravenously to humans because the compound is rapidly excreted by the kidneys. ${ }^{13}$ Aerosol administration may be an attractive route for clinical application. Studies in sheep have shown that aerosol administration of rSLPI significantly augments rSLPI levels in epithelial lining fluid. ${ }^{14}$ However, these studies also showed that the levels in lymphatic fluid of the lung, which can be regarded as representative of interstitial fluid, were 300400 times lower than levels in the bronchial lumen. The low concentration of rSLPI in the lymph may be explained by its selective association with elastin fibres present in lung interstitium due to the cationic charge of SLPI. ${ }^{5}$

Not much is known about the half life or even the production rate of endogenous SLPI in a human bronchial tree. Some studies have shown that SLPI is present in bronchoalveolar lavage (BAL) fluid and in sputum in nanomolar and millimolar concentrations, respectively. ${ }^{1516}$ Measurements of aerosolised rSLPI in BAL fluid by immunochemical methods are difficult to interpret because of the presence of endogenous SLPI. One approach to circumvent this problem is to use radiolabelled rSLPI. The aim of the present study was to determine the distribution and half life of aerosolised rSLPI labelled with $99 \mathrm{~m}$-technetium $\left({ }^{99 \mathrm{~m}} \mathrm{Tc}\right)$ in healthy individuals and in patients with cystic fibrosis or pulmonary emphysema associated with $\alpha_{1}$-antitrypsin deficiency of $\mathrm{ZZ}$ phenotype.

\section{Methods}

VALIDATION OF THE LABELLING METHOD

Human rSLPI was supplied by Synergen (Boulder, Colorado, USA) in vials of $100 \mathrm{mg}$ protein. Each vial was dissolved in $5 \mathrm{ml}$ saline and rSLPI was coupled to ${ }^{99 \mathrm{~m}} \mathrm{Tc}$ using a direct method as described for another protein. ${ }^{17}$ In brief, the 
rSLPI solution was incubated at room temperature with sodium ${ }^{99 \mathrm{~m}} \mathrm{Tc}$ pertechnetate and reducing agents such as $0.97 \mathrm{ng} / \mathrm{ml} \mathrm{SnCl}_{2}$, $116 \mathrm{ng} / \mathrm{ml}$ DTPA, and $97 \mathrm{ng} / \mathrm{ml} \mathrm{KBH}_{4}$ for 20 minutes. Labelling efficiency was 96 (1)\% $(\mathrm{n}=5)$ as assessed by reversed phase chromatography with an RP-18 lichrosorb column (Whatmann, Middleburg, Netherlands). After labelling, elastase inhibitory capacity and immunoreactivity were assayed as previously described. ${ }^{16}$ To test whether the radiolabel was still attached to the protein while present in the lung, 24 Golden Syrian hamsters each received $20 \mu \mathrm{g}$ rSLPI labelled with $0 \cdot 2 \mathrm{MBq}$ of ${ }^{99 \mathrm{~m}} \mathrm{Tc}$ in a volume of $200 \mu \mathrm{l}$ saline by the intratracheal route. In a period of 24 hours at eight different times, three hamsters were killed. The lungs were lavaged twice with $2.5 \mathrm{ml}$ saline. The fluid was centrifuged and the supernatant assayed for rSLPI by ELISA ${ }^{16}$ and counted for ${ }^{99 \mathrm{~m}} \mathrm{Tc}$ by a 1282 Compugamma counter (LKB Wallac, Turku, Finland) with correction for decay. Elastase inhibitory capacity of the supernatant was assayed as described. ${ }^{2}$ After the lung lavage the lungs were removed and homogenised, and rSLPI and ${ }^{99 \mathrm{~m}} \mathrm{Tc}$ activity determined.

\section{AEROSOL ADMINISTRATION TO HUMAN} INDIVIDUALS

This study was approved by the medical ethical board of the University Hospital Leiden and all male healthy volunteers and patients (age range 22-36 years) gave informed consent. Five healthy volunteers with normal pulmonary function tests each inhaled a solution of $100 \mathrm{mg}$ rSLPI in a volume of $5 \mathrm{ml}$ saline labelled with $185 \mathrm{MBq}{ }^{99 \mathrm{~m}} \mathrm{Tc}$ according to the method described above. The subjects inhaled the aerosol during 10 minutes while breathing at tidal volume. A Pariboy LL jet nebuliser (Pari Werke $\mathrm{GmbH}$, München, Germany) was used because this instrument was selected by the manufacturer of rSLPI for future therapeutic administration of the drug. For reasons of radiation hygiene, the trigger of the Pariboy was strapped with tape to generate the aerosol continuously during inspiration and expiration. Expired air was filtered by a Pall breathing system filter (Pall Ltd, Portsmouth, UK). The filter was mounted on the inhalation unit of the Pariboy. No valves were used during inspiration and expiration. Images of the chest were acquired with a digital gamma camera equipped with a low energy general purpose collimater (Toshiba GCA 501S, Tokyo, Japan). Immediately after all rSLPI was inhaled the lungs were imaged for five minutes at one hour intervals for the first eight hours with individuals in the supine position. The acquisition time was extended up to 20 minutes for images at 12 hours and 24 hours after inhalation. The disappearance of activity was measured in the total right lung and in a region of interest (ROI) in the right hilar region. The Pariboy chamber, tubing, and filter were counted in an identical fashion following aerosol delivery.
When the study with the five healthy volunteers was completed, five patients with emphysema associated with hereditary $\alpha_{1-}$ antitrypsin deficiency and three patients with cystic fibrosis were tested in a similar way. Patients were included in the study when their forced expiratory flow in one second was be- 응 tween $30 \%$ and $50 \%$ of predicted, measured after salbutamol inhalation. They inhaled the $\vec{F}$ aerosol while breathing at tidal volume seated $\stackrel{\odot}{\rightarrow}$ on a stool, with no specific medication used shortly before the aerosol inhalation started. $\frac{\bar{c}}{\mathrm{~s}}$ The disappearance rate of ${ }^{99 \mathrm{~m}}$ Tc-rSLPI was $\frac{{ }^{\circ}}{\mathrm{D}}$ measured in the total right lung and right hilar region.

To study further bronchial and tracheal dis- $\overrightarrow{0}$ appearance we measured the activity of ${ }^{99 \mathrm{~m}} \mathrm{Tc}-\overrightarrow{\vec{H}}$ rSLPI over the first two hours after aerosol $\stackrel{\omega}{\circ}$ inhalation by continuous data registration with $\overrightarrow{\vec{x}}$ the gamma camera in one healthy volunteer of and one patient with emphysema of $\mathrm{ZZ}$ phenotype in the supine position. Both individuals inhaled the aerosol as described above. Dis- of appearance was measured in the total right $ᄋ$ lung. Disappearance of activity in the hilus and $\vec{c}$ trachea was counted in small ROI over the right hilus and trachea, respectively.

\section{STATISTICAL ANALYSIS}

To analyse the mode of disappearance of ${ }^{99 \mathrm{~m}} \mathrm{Tc}-\bar{\partial}$ rSLPI from the lungs a non-linear regression $\stackrel{\circ}{\circ}$ procedure was applied using an SPSS program $~$ (SPSS Inc, Chicago, USA). Monoexponential $\overrightarrow{\overrightarrow{0}}$ and biexponential curve fitting was calculated by $y=\mathrm{A} \cdot \mathrm{e}^{-\mathrm{B} x}$ and $y=\mathrm{A} \cdot \mathrm{e}^{-\mathrm{B} x}+\mathrm{C} . \mathrm{e}^{-\mathrm{D} x}$, respectively. In biexponential disappearance rapid phase half life was calculated as $\ln 2 / \mathrm{B}$ and slow phase as $\ln 2 / \mathrm{D}$, respectively. The percentage of total deposition in the rapid phase was calculated as $(\mathrm{A} /(\mathrm{A}+\mathrm{C})) \times 100 \%$ and in the slow phase as $(\mathrm{C} /(\mathrm{A}+\mathrm{C})) \times 100 \%$, re- $\delta$ spectively. Curves were considered to be bi- $₹$ exponential if, in a semilogarithmic plot, a 9 biexponential graph showed a better fit than $D$ the monoexponential one and the corresponding sum of square differences differed substantially.

\section{Results}

VALIDATION OF LABELLING METHOD

Elastase inhibitory capacity and immunoreactivity in an ELISA of rSLPI labelled with ${ }^{99 \mathrm{~m}} \mathrm{Tc}$ were not different from unlabelled rSLPI (data not shown). When a solution of ${ }^{99 \mathrm{~m}} \mathrm{Tc}-\stackrel{\mathbb{D}}{\triangle}$ rSLPI was instilled in the trachea of hamsters the half life in BAL fluid was about 8 two hours. As can be seen in fig 1 the disappearance rate assessed by ${ }^{99 \mathrm{~m}} \mathrm{Tc}$ activity $(y \stackrel{)}{0}$ axis left) of the instilled solution did not differ from the rate as assayed by ELISA ( $y$ axis right). Figure 2 shows that lung homogenate of lungs instilled with ${ }^{99 m}$ Tc-rSLPI revealed similar disappearance rates to those seen in fig 1. These results indicate that ${ }^{99 \mathrm{~m}} \mathrm{Tc}$-rSLPI is quite stable while present in the hamster lung. 


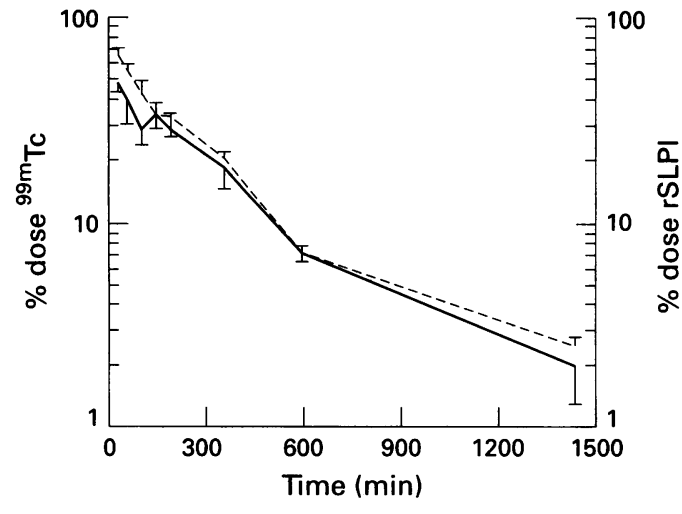

Figure 1 Disappearance of ${ }^{99 m} T c-r S L P I$ with time from lung lavage fluid of hamsters after intratracheal instillation of $20 \mu \mathrm{g} r S L P I$. The left $y$ axis shows the clearance of ${ }^{99 m} T c$ (solid line) expressed as percentage activity of the instilled material. The right $y$ axis shows $r S L P I$ as a percentage of the original instilled material (dashed line) in the same samples as assayed by ELISA. Values represent mean (SE) for three animals.

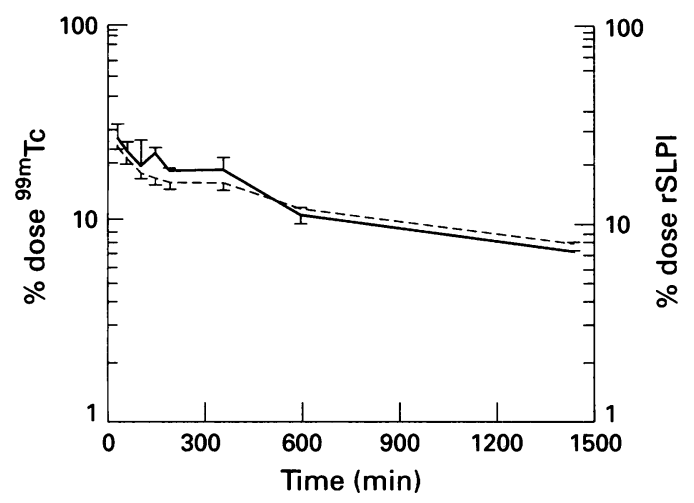

Figure 2 Disappearance of ${ }^{99 m} T c-r S L P I$ from homogenised hamster lungs after lung lavage. The right and left $y$ axes represent data as described in the legend of fig 1 .
HUMAN IN VIVO STUDIES

All individuals inhaled no more than $10 \%$ of the delivered aerosol into the lungs. About $70 \%$ was retained in the outflow filter and $20 \%$ was deposited in the mouth and reached the stomach. No side effects of the aerosol were noticed. The distribution of aerosolised ${ }^{99 \mathrm{~m}} \mathrm{Tc}$ rSLPI in one representative healthy individual at one hour after inhalation is shown in fig 3A. The scintigram demonstrates a homogeneous distribution of activity over all lung lobes. We chose to measure activity of ${ }^{99 \mathrm{~m}} \mathrm{Tc}-\mathrm{rSLPI}$ in the right lung because stomach deposition made it difficult to indicate the margins of the left lung. The calculated half life of ${ }^{99 \mathrm{~m}} \mathrm{Tc}-\mathrm{rSLPI}$ in the total right lung of five normal subjects is shown in the table. When fitting curves to the data obtained a monoexponential curve was adequate for two cases (volunteers 3 and 5); for the others a biexponential curve was preferred. As can be seen in the table, a rapid component of disappearance from the total right lung existed with half life of approximately four hours. Slow phase half life was more than 63 hours. About $75 \%$ of the deposited radiolabel in the lung disappeared in the slow phase.

The distribution of the radiolabel in the lungs of patients with emphysema and cystic fibrosis was patchy (fig $3 \mathrm{~B}$ and $3 \mathrm{C}$ ). Emphysematous areas in the lower lobes, as observed on diagnostic ventilation scintigrams with ${ }^{81 \mathrm{~m}} \mathrm{Kr}$ gas (data not shown), were poorly filled with the SLPI aerosol (fig 3B). In patients with cystic fibrosis, hot spots were observed in hilar regions and in peripheral parts of both lungs (fig 3C). The disappearance of rSLPI from the right lung of patients with emphysema and cystic fibrosis was biphasic in both patient groups. None of the curves fitted into a monoexponential plot. The rapid disappearance of rSLPI from the total right lung in patients with emphysema had a mean (SE) half life of 1.52 $(0 \cdot 79)$ hours (table) and contained $37 \cdot 8(8 \cdot 7) \%$ of total material deposited in the lung. The slow phase half life was 64 (30) hours $(n=$

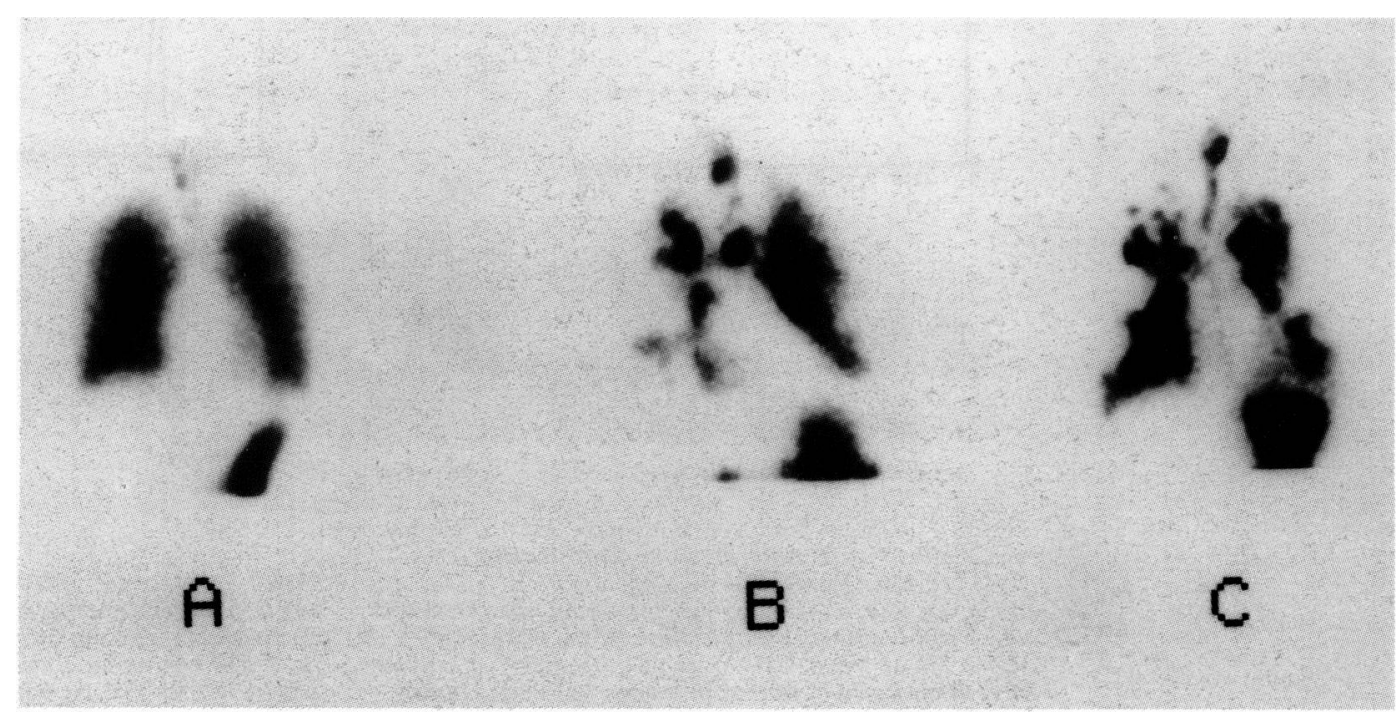

Figure 3 Distribution of aerosolised ${ }^{99 m} T c-r S L P I$ in $(A)$ a representative normal individual, (B) a patient with emphysema, and $(C)$ a patient with cystic fibrosis one hour after inhalation. Homogeneous distribution over all areas of both lungs is seen in the normal individual. Deposition in the stomach (as seen in the lower right corner of each of the images) disappeared three hours after inhalation. The distribution in both patients was patchy. 
Calculated data of ${ }^{99 m}$ Tc-rSLPI in the total right lung of normal individuals and patients with emphysema and cystic fibrosis

\begin{tabular}{|c|c|c|c|c|c|}
\hline & Subject no. & Rapid half life (h) & Slow half life $(h)$ & Deposition (\% rapid) & Deposition (\% slow) \\
\hline Normal subjects & $\begin{array}{l}1 \\
2 \\
3^{*} \\
4 \\
5^{*}\end{array}$ & $\begin{array}{l}3 \cdot 86 \\
4 \cdot 18 \\
4 \cdot 77 \\
-\end{array}$ & $\begin{array}{r}305 \\
63 \\
29 \\
150 \\
36\end{array}$ & $\begin{array}{l}32 \\
16 \\
- \\
28 \\
-\end{array}$ & $\begin{array}{l}68 \\
84 \\
- \\
72 \\
-\end{array}$ \\
\hline Emphysema & $\begin{array}{r}6 \\
7 \\
8 \\
9 \\
10\end{array}$ & $\begin{array}{l}2.62 \\
1.14 \\
2.09 \\
1.02 \\
0.74\end{array}$ & $\begin{array}{c}-66 \dagger \\
42 \\
66 \\
108 \\
43\end{array}$ & $\begin{array}{l}38 \\
38 \\
41 \\
24 \\
48\end{array}$ & $\begin{array}{l}62 \\
62 \\
59 \\
76 \\
52\end{array}$ \\
\hline Cystic fibrosis & $\begin{array}{l}11 \\
12 \\
13\end{array}$ & $\begin{array}{l}2 \cdot 27 \\
2 \cdot 22 \\
2 \cdot 51\end{array}$ & $\begin{array}{r}81 \\
143 \\
80\end{array}$ & $\begin{array}{l}27 \\
43 \\
45\end{array}$ & $\begin{array}{l}73 \\
57 \\
55\end{array}$ \\
\hline
\end{tabular}

* The curves of these volunteers fitted better in a monoexponential model.

$\dagger$ This value is negative because the activity of the aerosol at 24 hours was higher than at 12 hours in this patient. When the value $\overrightarrow{0}$ at 24 hours is deleted the slow half life is 195 hours.

4). More than half of the deposited rSLPI disappeared in the slow phase of the curve. In patients with cystic fibrosis the rapid phase half life of rSLPI in the total right lung was 2.33 $(0 \cdot 15)$ hours while the slow half life was more than 42 hours. The rapid phase of disappearance represented $38(9 \cdot 8) \%$ of all rSLPI deposited in the lung.

In order to investigate further bronchial and tracheal movement of the radiolabel in the rapid phase of ${ }^{99 \mathrm{~m}} \mathrm{Tc}$-rSLPI disappearance we measured ${ }^{99 \mathrm{~m}} \mathrm{Tc}$ activity in one healthy volunteer during two hours of continuous recording.
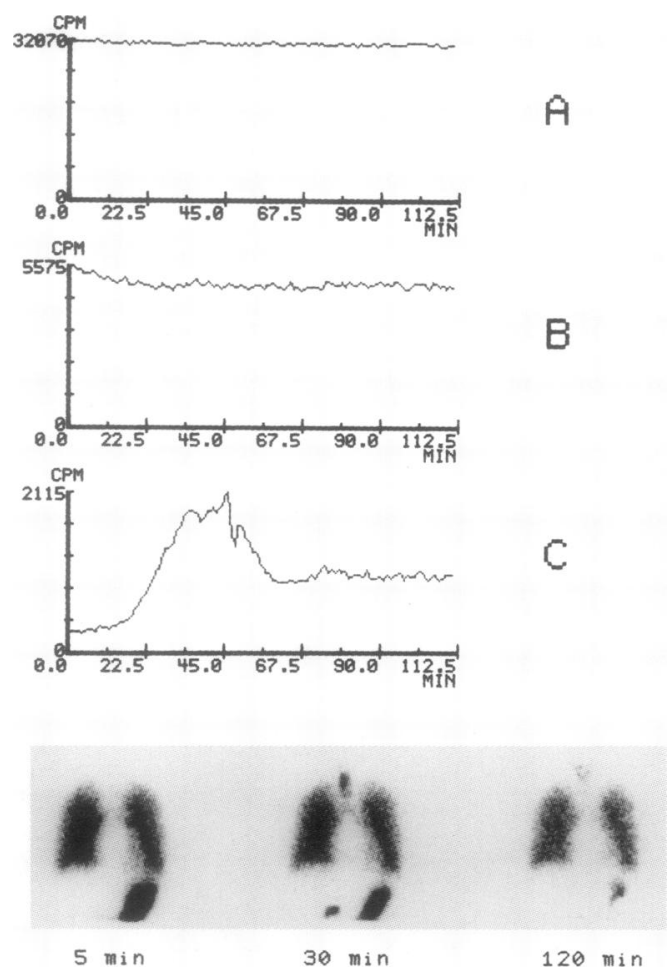

Figure 4 Disappearance of aerosolised ${ }^{99 m}$ Tc-rSLPI from one healthy volunteer during continuous imaging for a period of 120 minutes after inhalation of aerosol. The disappearance from the total right lung $(A)$ and from a small region of interest in the centre of the right hilar region (B) or trachea (C) is shown. Transport of activity in a small region of interest in the trachea varied during the first 60 minutes but remained stable afterwards.

Images at selected time points after inhalation of aerosol (5, 30, and 120 minutes) are presented to show ${ }^{99 m} \mathrm{Tc}$ activity passing the trachea, being most pronounced at 30 minutes.
Figure 4 shows the decline in activity as a linear plot of ${ }^{99 \mathrm{~m}} \mathrm{Tc}$ in the total right lung (fig 4A). Changes in activity with time in a small ROI's located in the hilar region are shown in fig 4B. A Less than $10 \%$ of the initial counts disappearedo and at 30 minutes after aerosol inhalation $a^{?}$ steady state phase occurred. Disappearance of ${ }^{99 \mathrm{~m}} \mathrm{Tc}$-rSLPI in an ROI in the trachea towards the oral cavity occurred up to 60 minutes after $\vec{\bullet}$ inhalation (fig 4C).

Central deposition of activity in the lungs was much more pronounced in the individual with emphysema (fig 5). In the total right lung
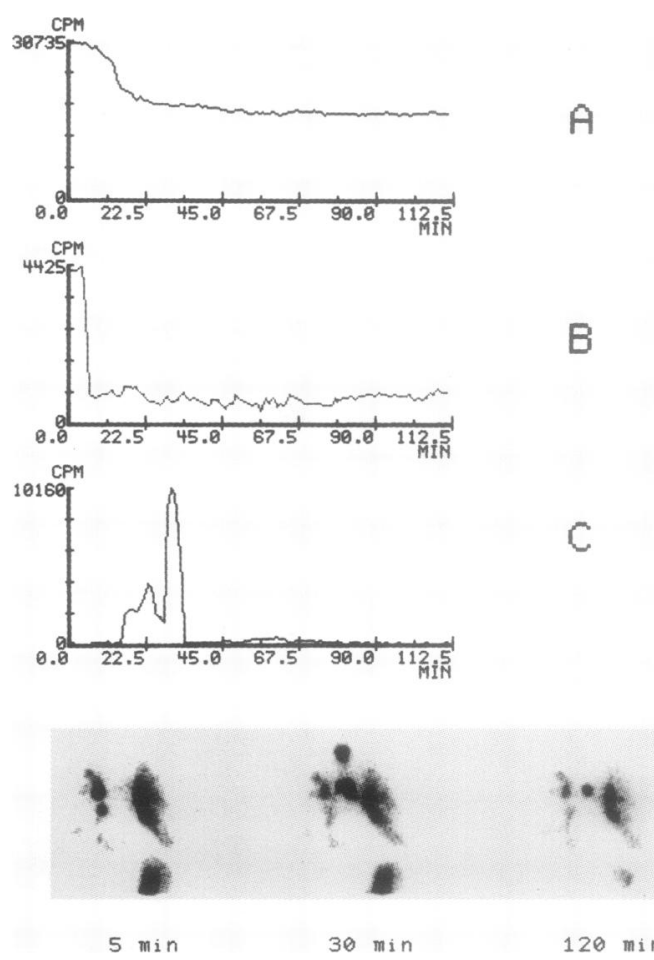

Figure 5 Disappearance of aerosolised ${ }^{99 m} T c-r S L P I$ from one patient with emphysema of PiZZ phenotype. Graphs $A, B$, and $C$ represent areas as explained in the legend of fig 4. Disappearance of activity from the total right lung occurred in the first 20 minutes and activity remained at a stable level afterwards. Activity in a small region of interest in the right hilar region declined by $80 \%$ and remained at a steady level thereafter. Images at 5, 30 and 120 minutes clearly show passage of activity in time, as plotted in graph (C). 
$40 \%$ of the deposited activity disappeared in the first 20 minutes after inhalation (fig 5A). The activity in a small ROI in the hilar region declined by $80 \%$ in 10 minutes and remained stable at about $20 \%$ during the next $110 \mathrm{~min}$ utes (fig 5B). In an ROI in the trachea ${ }^{99 \mathrm{~m}} \mathrm{Tc}-$ rSLPI passed in the first 60 minutes only (fig 5C). The patient did not cough during the recording period.

\section{Discussion}

This study has shown that deposition of aerosolised rSLPI occurs in well ventilated areas of the human lung and that the disappearance in patients with bronchial obstruction is biphasic with a rapid half life shorter than five hours and a slow half life longer than 24 hours. We have established that the radiolabel remained attached to the protein while in the airways because the ratio of measured rSLPI levels and ${ }^{99 \mathrm{~m}} \mathrm{Tc}$ counts in BAL fluid in hamsters did not differ from the ratio of the instilled material.

The aerosol was generated continuously in the Pariboy because the trigger was taped to reduce the radiation burden for the volunteers. There were no valves in the tubing system connected to the patient and the filter. This procedure most probably caused the high deposition of ${ }^{99 \mathrm{~m}} \mathrm{Tc}-\mathrm{rSLPI}$ in the filter. The ratio between deposition in the lung and the oropharynx plus stomach is similar to results obtained with other aerosol delivery systems. ${ }^{1819}$ This indicates that breathing at tidal volume, sitting on a stool, under the experimental conditions as described, resulted in efficient deposition of rSLPI in both healthy volunteers and patients with COPD. Within the lung, several factors may influence the site of particle deposition. ${ }^{20}$ Increased central deposition by impaction occurs with increasing inspiratory flow rate. A breath-hold of up to 10 seconds after inhalation enhances drug deposition by allowing longer for sedimentational deposition. ${ }^{20}$ Also, a decrease in airway calibre may increase deposition in the central airways by increasing turbulent airflow. In fact, the latter deposition pattern was observed in our patients with emphysema and cystic fibrosis. Distribution was patchy and hot spots were seen in several fields of the lung. In patients with emphysema these hot spots may represent bronchi being obstructed by extrabronchial pressure from bullae in emphysema. In patients with cystic fibrosis the spots may be caused by widened carinae of narrowed bronchi due to mucosal inflammation or by bronchi obstructed with mucus plugs. The Pariboy jet nebuliser is frequently used for aerosolisation of bronchodilating and mucolytic drugs. We found it outside the scope of this study to measure particle size of the SLPI aerosol, given the numerous other variables which may be responsible for the results we obtained. We have previously shown that the Pariboy does not produce particle sizes which are very different from other jet nebulisers. ${ }^{18}$

In emphysematous patients deposition of rSLPI coincided with ventilated areas seen on $a^{81 \mathrm{~m}} \mathrm{Kr}$ ventilation scintigram (data not shown).
This deposition pattern of rSLPI may be efficacious in protecting normal alveolar architecture from further tissue destruction by proteases. Areas which have been destroyed and are poorly ventilated need no further protection by rSLPI, since the lung has no capacity to regenerate new alveoli. In patients with cystic fibrosis it is desirable to deposit rSLPI in well ventilated areas for protection of lung tissue against proteases, but it is also needed in poorly ventilated areas which are most likely to contain bronchial walls infiltrated with neutrophils. A recent study in patients with cystic fibrosis showed that active neutrophil-derived elastase levels in BAL fluid were still present after treatment with an aerosol of rSLPI at a dose of $100 \mathrm{mg}$ twice daily for seven days. ${ }^{21}$ These results were obtained by analysing BAL fluid before and after treatment. In patients with cystic fibrosis BAL fluid probably represents a mixture of fluid from well and poorly ventilated areas. Thus the observed patchy deposition of rSLPI seen in fig 3C may explain why not all elastase activity was neutralised by the inhibitor in this study. ${ }^{21}$

Similar disappearance rates were found in all individuals irrespective of their disease states. The disappearance was biphasic as predicted in studies by Morrow and $\mathrm{Yu}$ in humans ${ }^{22}$ and Smith et al in dogs. ${ }^{23}$ Morrow and $\mathrm{Yu}$ proposed that the first (rapid) phase of clearance in a semilog plot represented transport of insoluble particles by ciliated epithelium in the bronchial tree. The slow second phase should represent alveolar clearance. In contrast to Morrow and $\mathrm{Yu}$, we used an aerosol which contained a soluble protein. In a study in dogs, Smith et al found that an aerosol of human $\alpha_{1}$-antitrypsin disappeared from mechanically ventilated lungs with an initial half life of 12 hours, slowing to a late phase half life of 50 hours, measured from total lung scintigrams. By plotting our data in a similar fashion we found rapid phase half life values of less than five hours obtained from total lung scintigrams. By measuring only at the area of the right hilum the rapid phase half life declined to less than three hours (data not shown). This suggests a rapid disappearance of the deposited rSLPI in the ciliated bronchial airways. Although we found no correlation between rSLPI levels and elastase activity in BAL fluid, our results imply that treatment of bronchial diseases with rSLPI should be performed by frequent daily inhalation to obtain adequate levels of elastase inhibitory capacity. We did not find it valuable to study the rapid phase half life more accurately because it would not essentially change the result and only lead to radiation burden on more volunteers.

The slow disappearance of deposited technetium counts during the late phase indicates that rSLPI remains in non-ciliated airways and alveoli for more than 24 hours. This is ideal for diffusion through the epithelial barrier into the interstitium to protect against elastase-mediated tissue destruction. Studies in hamsters have shown that rSLPI instilled into the lungs is able to inhibit elastase activity from hamster neutrophils present in alveolar walls. ${ }^{24}$ This 
indicates that this low molecular mass molecule $(12 \mathrm{kD})$ is able to diffuse to sites of inflammation in lung interstitium. As shown in the table, more than $50 \%$ of the total deposited material in the lung is cleared during the slow phase, indicating deposition in the alveolar air spaces. Taken together, these results suggest that aerosol administration of rSLPI by Pariboy is appropriate for the treatment of pulmonary emphysema in patients with inherited $\alpha_{1}$-antitrypsin deficiency.

In summary, we have shown that aerosols of rSLPI can be produced that deposit in central and peripheral parts of the lung of normal volunteers and patients with emphysema and cystic fibrosis. Peripheral parts of the lung cleared rSLPI at a very slow rate, irrespective of the presence of disease in the lung. Central deposition tended to vary with the presence of ventilation impairment. The results imply that therapeutic administration of rSLPI by aerosol will probably protect functional lung tissue from further proteolytic damage, whereas highly inflamed areas or bullae with poor ventilation will probably benefit less. Future long term clinical investigations are needed to obtain further proof of the beneficial effects of rSLPI aerosol inhalation in inhibiting progression of neutrophil-mediated tissue destruction.

The authors thank Dr HGM Heijerman, Department of Pulmonology at Leyenburg Hospital, The Hague, The Netherlands for the participation of two patients with cystic fibrosis.

The drug was kindly supplied by Synergen Inc (Boulder, Colorado, USA) who also supported the study with a grant.

1 Thompson RC, Ohlsson $\mathrm{K}$. Isolation properties and complete amino acid sequence of human secretory leucocyte protease inhibitor, a potent inhibitor of leucocyte elastase. protease inhibitor, a potent inhibitor
Proc Natl Acad Sci 1986;83:6692-6.

2 Kramps JA, van Twisk C, Appelhans H, Meckelein B, Nikiforov T, Dijkman JH. Protease inhibitory activities of antileukoprotease are presented by its second $\mathrm{COOH}-$ terminal domain. Biochim Bophys Acta 1990;1038:178-85.

3 De Water R, Willems LNA, van Muyen GNP, Franken C, Fransen JAM, Dijkman JH, et al. Ultrastructural locations of bronchial antileukoprotease in central and peripheral human airways by a gold-labelling technique using monoclonal antibodies. Am Rev Respir Dis 1986;133:882-90.

4 Dijkman JH, Kramps JA, Franken C. Antileukoprotease in sputum during bronchial infections. Chest 1986;89:731-6.

5 Kramps JA, te Boekhorst AHT, Fransen JAM, van Ginsel $\mathrm{JA}$, Dijkman JH. Antileukoprotease is associated with elastin fibres in the extracellular matrix of the human lung Am Rev Respir Dis 1989;140:471-6.

6 Depuit F, Jacquot J, Benali J, Hinnrasky R, Puchelle E. Apical and basolateral secretion of proteins by human tracheal gland cells cultured on a permeable substra. Epithel Cell Biol 1993;2:91-9.

7 Suters S. The imbalance between granulocyte neutral proteases and antiproteases in bronchial secretions from patients with cystic fibrosis. In: Pseudomonas aeruginos infection. Antibiot Chemother (Basel) 1989;42:158-68.

8 Stockley RA, Morrison HM, Kramps JA. Studies of proteases and their inhibitors in lung

9 Tosi MF, Zakem H, Berger M. Neutrophil elastase cleaves C3bi on opsonized Pseudomonas as well as CR1 on neutrophils to create a functionally important opsonin receptor mismatch. F Clin Invest 1990;86:300-8.

10 Tosi $M$, Berger $M$. Functional differences between the $40 \mathrm{kDa}$ and 50 to $70 \mathrm{kDa}$ IgG Fc $\gamma$ receptors on human neutrophils revealed by elastase treatment and receptor antibodies. F Immunol 1989;141:2097-103.

11 Sommerhoff CP, Nadel JA, Basbaum CB, Caughy GH Neutrophil elastase and cathepsin G stimulate secretion from cultured bovine airways gland serous cells. $\mathcal{F}$ Clin from cultured bovine

12 Eisenberg SP, Hale KK, Heimdal P, Thompson RC. Location of the protease-inhibitory region of secretory leucocyte protease inhibitor. $\mathcal{F}$ Biol Chem 1990;265:7976-81.

13 Gast A, Anderson W, Probst A, Nick H, Thompson RC, Eisenberg SP, et al. Pharmacokinetics and distribution of recombinant secretory leucocyte protease inhibitor in rats. Am Rev Respir Dis 1990;141:889-94.

14 Vogelmeier C, Buhl R, Hoyt RF, Wilson E, Fells GA, Hubbard RC, et al. Aerosolization of recombinant SLPI to augment antineutrophil elastase protection of pulmonary epithelium. $\mathcal{F}$ Appl Physiol 1990;69:1843-8.

15 Kramps JA, Franken C, Dijkman JH. Quantity of antileukoprotease relative to $\alpha_{1}$-protease inhibitor in peripheral airspaces of the human lung. Clin Sci 1988;75:351-3.

16 Kramps JA, Franken C, Diikman JH. ELISA for quantitative measurement of low-molecular-weight bronchial protease inhibitor in human sputum. Am Rev Respir Dis 1984;129: 958-63.

17 Pauwels EKJ, Welling MM, Feitsma RIJ, Atsma DE, Nieuwenhuizen $W$. The labelling of proteins and LDL with ${ }^{99 m}$ Tc: a new direct method employing $\mathrm{KHB}_{4}$ and stannous chloride. Nucl Med Biol 1993;20:825-30.

18 Sterk PJ, Plomp A, van de Vate JF, Quanjer PH. Physical properties of aerosols produced by several jet- and ultrasonic nebulizers. Bull Eur Physiopathol Respir 1984;20: 65-72.

19 Stahlhofen W, Gebhart J, Heyder J, Scheuch G. Deposition pattern of droplets from medical nebulizers in the human respiratory tract. Bull Eur Physiopathol Respir 1983;19. 459-63.

20 Brain JD, Valberg PA. Deposition of aerosol in the respiratory tract. Am Rev Respir Dis 1979;120:1325-73.

21 McElvaney NG, Doujaiji B, Moan MJ, Burnham MR Wu MC, Crystal RG. Pharmacokinetics of recombinan secretory leukoprotease inhibitor aerosolized to normals and individuals with cystic fibrosis. Am Rev Respir Dis 1993;148:1056-60.

22 Morrow PE, Yu CP. Models of aerosol behaviour in airways In: Morén F, Newhouse MT, Dolovich MB, eds. Aerosol in medicine, Principles, diagnosis and therapy. Amsterdam Elsevier, 1982:149-92.

23 Smith RM, Traber LD, Traber DL, Spragg RG. Pulmonary deposition and clearance of alpha-1-protease inhibito administered to dogs and to sheep. 7 Clin Invest $1989 ; 84$ administer

24 Rudolphus A, Stolk J, van Twisk C, van Noorden CJF, Dijkman JH, Kramps JA. Detection of extracellular neutrophil elastase in hamster after intratracheal instillation of $E$ coli lipopolysaccharide using a fluorogenic, elastasespecific, synthetic substrate. Am ₹ Pathol 1992;141:153 60 . 